\title{
Detecção de locos de características quantitativas nos cromossomos 16 , 17 e 18 de suínos
}

\section{Débora Martins Paixão', Simone Eliza Facioni Guimarães², Miguel Inácio da Silva Filho, Paulo Sávio Lopes ${ }^{2}$, Mário Sérgio Pereira ${ }^{3}$, Bruna Pena Solero ${ }^{1}$}

\author{
1 Programa de Pós-graduação em Zootecnia - UFV. \\ 2 Departamento de Zootecnia, Universidade Federal de Viçosa, Viçosa, Minas Gerais, CEP: 36570-000. \\ 3 Técnico de Laboratório do Departamento de Zootecnia, Universidade Federal de Viçosa, Viçosa, Minas Gerais, CEP: 36570-000.
}

RESUMO - Objetivou-se com este trabalho realizar o mapeamento de Locos de características quantitativas (QTL) nos cromossomo 16, 17 e 18 de suínos e associar seus efeitos com características de desempenho. Utilizou-se uma população F2 proveniente do cruzamento de dois varrões da raça naturalizada brasileira Piau com 18 fêmeas de linhagem comercial (Landrace $\times$ Large White $\times$ Pietrain). A população foi genotipada para 11 marcadores microssatélites e o mapa de ligação específico dos marcadores para a população foi construído. Os marcadores de microssatélites foram considerados adequados para estudos de características quantitativas quando analisado o conteúdo de informação polimórfica (PIC). Para identificação do QTL, utilizou-se o método de regressão por intervalo de mapeamento e realizaram-se as análises por meio do programa QTLExpress. Foram detectados QTL não descritos na literatura para: número de tetas no cromossomo 16; peso aos 63 e aos 77 dias de idade no cromossomo 17; e peso aos 21 dias e idade de abate no cromossomo 18. Foram também identificados QTL já descritos em outras populações, como para peso aos 21 dias de idade no SSC16. As informações dos QTL significativos encontrados servem para futuros estudos de mapeamento fino com identificação de genes e para maior entendimento dos fenótipos produtivos de suínos.

Palavras-chave: análise genômica, população F2, produção de suínos

\section{Detection of QTL for production traits on swine chromosomes 16, 17 and 18}

\begin{abstract}
The objectives of this study were to map Quantitative Trait Loci (QTL) in chromosomes 16, 17 and 18 and to associate their effects with performance traits in a F2 pig population developed by mating two Brazilian Piau sires with 18 crossbred dams (Landrace $\times$ Large White $\times$ Pietrain). The linkage map for this population was constructed after genotyping the animals for 11 microsatellite markers and scoring the genotype. Estimates of polymorphic information content (PIC) indicated that the microsatellite markers were appropriate for QTL analyses. Data were analyzed by interval mapping using the QTLEXPRESS program. New QTL were identified for teat number on SSC16, weight at 63 and 77 days of age on SSC17, weight at 21 days of age and slaughter age on SSC18. QTL already known in other populations were also identified for weight at 21 days of age on SSC16. The information of the significant QTL detected in this study is useful for future fine-mapping studies for identification of genes and to improve the knowledge about production traits in pig populations.
\end{abstract}

Key Words: F2 population, genomic analysis, pig production

\section{Introdução}

Locos de Características Quantitativas (QTL) sãogenes localizados no genoma e que têm efeitos genéticos aditivos, dominantes e/ou epistáticos significativos (Liu, 1998). Os marcadores de microssatélites foram propostos como uma das melhores opções para o mapeamento desses locos (Beckmann \& Soller, 1990; Chin et al., 1996), pois possuem potencial de constituir um perfil alélico único (DNA fingerprinting), padrão de herança mendeliana, caracterís- tica co-dominante, em geral elevado conteúdo de informação de polimorfismo (PIC), e reprodutibilidade.

A detecção de QTL permite identificar no genoma regiões onde se encontram gene ou genes que controlam parte das diferenças fenótipicas. Segundo Plastow (2000), a identificação de genes influenciando características economicamente importantes, seguida pela seleção assistida por marcadores, pode ser empregada em conjunto com métodos tradicionais de seleção para aumentar a acurácia da seleção e melhorar a resposta à seleção. A seleção para 
características de desempenho é importante, pois aumenta a eficiência na produção de suínos e resulta em animais com melhor conversão alimentar e maiores ganhos médios diários, reduzindo a idade de abate.

O objetivo neste estudo foi a detecção de QTL localizados nos cromossomos 16 (SSC16), 17 (SSC17) e 18 (SSC18), após medição de características de desempenho na geração F2 produzida por cruzamentos entre populações geneticamente divergentes formadas a partir de machos da raça naturalizada Piau e fêmeas comercias (Landrace $\times$ Large White $\times$ Pietrain).

\section{Material e Métodos}

A formação da população e a coleta dos dados fenotípicos foram realizados na Granja de Melhoramento de Suínos do Departamento de Zootecnia da Universidade Federal de Viçosa (UFV), em Viçosa, Minas Gerais, Brasil, no período de novembro de 1998 a julho de 2001. Foi construída uma população F2 proveniente do cruzamento de dois varrões da raça naturalizada brasileira Piau com 18 fêmeas de linhagem desenvolvida na UFV pelo acasalamento de animais de raça comercial (Landrace $x$ Large White $\times$ Pietrain) selecionados para desempenho. Maiores detalhes sobre a constituição da população foram descritos por Band et al. (2005a,b), Faria et al. (2006) e Peixoto et al. (2006).

Os machos da geração $\mathrm{F} 2$ foram castrados com 10 dias de idade e todos os leitões foram desmamados aos 21 dias de idade. No período dos 77 aos 105 dias de idade, os animais foram submetidos ao teste de conversão alimentar individual. O abate dos animais foi realizado por insensibilização elétrica quando o animal atingiu peso vivo médio de $65 \mathrm{~kg}$. Antes do abate, os animais foram mantidos com dieta líquida por 18 horas.

As seguintes características de desempenho foram mensuradas na geração F2: conversão alimentar (CA) dos 77 aos 105 dias, consumo de ração (CR) dos 77 aos 105 dias, ganho de peso médio diário (GPD), número de tetas (NT), peso ao nascer (PN), pesos aos 21, 42, 63, 77 e aos 105 dias, peso ao abate (PA) e idade ao abate (IDA) aos $65 \mathrm{~kg}$ de peso vivo médio. As três primeiras características foram medidas com os animais isolados em gaiolas individuais. O número de observações, as médias, os desvios-padrão e os valores máximos e mínimos destas características (Tabela 1) foram obtidos por meio do PROC MEANS do SAS (2000).

A extração do DNA das amostras de sangue e a análise genotípica dos animais parentais F1 e F2 foram conduzidas no Laboratório de Biotecnologia Animal do Departamento
Tabela 1 - Número de observações, média e desvio-padrão para as características estudadas

\begin{tabular}{lccc}
\hline Característica & No observações & Média & Desvio-padrão \\
\hline Conversão alimentar & 591 & 2,79 & 0,65 \\
dos 77 aos 105 dias & & & \\
de idade (kg/kg) & & & \\
Consumo de ração & 598 & 39,80 & 8,35 \\
dos 77 aos 105 dias & & & \\
de idade (kg) & & & \\
Ganho de peso diário (kg) & 591 & 0,53 & 0,13 \\
Número de tetas & 800 & 13,16 & 1,28 \\
Peso ao nascer (kg) & 800 & 1,20 & 0,28 \\
Peso aos 21 dias (kg) & 665 & 4,87 & 1,18 \\
Peso aos 42 dias (kg) & 665 & 8,24 & 1,98 \\
Peso aos 63 dias (kg) & 656 & 16,21 & 3,43 \\
Peso aos 77 dias (kg) & 602 & 21,42 & 4,38 \\
Peso aos 105 dias (kg) & 595 & 36,26 & 6,74 \\
Peso ao abate (kg) & 510 & 64,74 & 5,62 \\
Idade ao abate (dias) & 521 & 147,94 & 10,61 \\
\hline
\end{tabular}

Tabela 2 - Características dos marcadores usados para detecção de QTL nos cromossomos 16, 17 e 18 de suínos

\begin{tabular}{lccccc}
\hline SSC $^{1}$ & Marcador & $\begin{array}{c}\text { Tamanho } \\
\text { alelos }\end{array}$ & $\begin{array}{c}\text { Número } \\
\text { alelos }\end{array}$ & $\begin{array}{c}\mathrm{T}^{2} \\
\text { de PCR }\end{array}$ & No ciclos \\
\hline 16 & S0006 & $212-242$ & 5 & 58 & 40 \\
16 & SW977 & $96-102$ & 3 & 58 & 40 \\
16 & SW2517 & $161-189$ & 5 & 58 & 40 \\
16 & SW1897 & $154-170$ & 3 & 62 & 40 \\
17 & SW24 & $94-1114$ & 5 & 58 & 25 \\
17 & SW2142 & $130-146$ & 4 & 60 & 28 \\
17 & S0359 & $253-277$ & 6 & 58 & 32 \\
17 & SW2427 & $117-133$ & 5 & 50 & 40 \\
18 & SW1984 & $138-160$ & 5 & 55 & 32 \\
18 & S0120 & $150-168$ & 6 & 58 & 25 \\
18 & S0177 & $139-171$ & 7 & 50 & 25 \\
\hline
\end{tabular}

${ }^{1}$ Cromossomo, ${ }^{2}$ temperatura de anelamento em ${ }^{\circ} \mathrm{C}$.

de Zootecnia da UFV, como descrito previamente por Band et al. (2005a,b).

Foram utilizados 11 pares de primers de marcadores microssatélites distribuídos nos cromossomos 16,17 e 18 (Tabela 2).

As amplificações foram feitas em termocicladores MJ Research PTC 100-96 ${ }^{\circledR}$. As reações foram constituídas de água bidestilada, Taq DNA polimerase (Phoneutria) $1 \mathrm{U}$, Tampão IB 10X (Phoneutria), DNTPs 0,2 mM, primer foward e reverse 0,2 mM cada um, $25 \mathrm{ng}$ de DNA genômico por reação e volume final de $15 \mathrm{~mL}$. O DNA amplificado foi visualizado em gel de poliacrilamida $8 \%$ para verificação do tamanho e da intensidade das bandas e a existência de bandas inespecíficas. Após a confirmação das amplificações, o escoreamento dos fragmentos amplificados foi feito 
utilizando-se o software GenScan (Applied Biosystems) por meio de seqüenciador automático ABI PRISM 310.

As informações de freqüência de alelos (ñi), heterozigozidade esperada (He) e observada (Ho) e o conteúdo de informação de polimorfismo (PIC) dos marcadores de microssatélites dos 20 animais parentais, 64 animais $\mathrm{F} 1 \mathrm{e}$ de aproximadamente 500 animais F2, foram coletadas utilizando-se o programa CERVUS versão 2.0 (Marshall et al., 1998).

Para construção do mapa de ligação dos SSC16, SSC17 e SSC18, utilizou-se o programa CRIMAP (Green et al., 1990). Os dados de genótipo, fenótipo e o mapa de ligação gerado foram submetidos ao programa QTLExpress (Seaton et al., 2002) para detecção de QTL.

No modelo estatístico utilizado, assumiu-se que o QTL é dialélico e com alelos alternativos fixados em cada raça parental. A probabilidade de cada indivíduo F2 apresentar cada um dos três genótipos do QTL é calculada conforme o genótipo dos marcadores, a intervalos de $1 \mathrm{cM}$ ao longo do cromossomo. Essas probabilidades são usadas para se fazer a regressão das características nos coeficientes aditivos e de dominância do QTL em estudo, para cada animal, como descrito por Haley et al. (1994).

A determinação dos limiares de significância cromossômica ( $a=0,05$ e $a=0,01)$ foi feita no programa QTLEXPRESS, com testes de 10.000 permutações (Churchill \& Doerge, 1994). O intervalo de confiança a 95\% (IC95\%) para a localização do QTL foi obtido usando a aproximação de Qui-quadrado $\left(X^{2}\right)$, conforme descrito por Pérez-Enciso et al. (2000). Neste estudo foram estimados os efeitos aditivos, de dominância e deimprinting. O seguinte modelo estatístico foi ajustado aos dados:

$$
y_{i j k l}=S_{i}+L_{j}+H_{k}+\left(C_{i j k l}-\bar{C}\right) b+c_{a} a+c_{d} d+e_{i j k l}
$$

em que: $y_{i j k}=$ fenótipo; $S_{i}=$ efeito fixo do sexo $i, i=1$ (macho), 2(fêmea); $L_{j}=$ efeito fixo do lote ou da época de parição $j$, $\mathrm{j}=1,2,3,4,5 ; \mathrm{H}_{\mathrm{k}}=$ efeito fixo do genótipo do gene do halotano $\mathrm{k}, \mathrm{k}=1(\mathrm{NN}), 2(\mathrm{Nn}) ;\left(\mathrm{C}_{\mathrm{ijk}}-\overline{\mathrm{C}}\right) \mathrm{b}=$ ajustamento para as co-variáveis.

Entre as características de desempenho descritas, foram usadas como co-variáveis o tamanho de leitegada ao nascimento parapeso ao nascer, o tamanho da leitegada ao desmame para P21, P42, P63, P77, P105 e PA e o peso aos 77 dias para consumo de ração, ganho de peso diário e conversão alimentar.

O genótipo para o gene halotano foi incluído como efeito fixo, uma vez que Band et al. (2005a,b) observaram não apenas a presença da mutação Hal1843 nesta população, mas também seus efeitos $(\mathrm{P}<0,05)$ sobre características de desempenho, carcaça e qualidade de carne.
A fração aditiva da variância fenotípica $\left(\hat{h}_{Q}^{2}\right)$ da F2 explicada por determinado QTL foi computada conforme descrito por Pérez-Enciso et al. (2000), assumindo-se que alelos alternativos estão fixados em cada raça, $\hat{h}_{Q}^{2}=a^{2} / 2 \hat{\sigma}_{y}{ }^{2}$, de modo que: $\hat{\sigma}_{Y}=$ desvio-padrão residual considerando os efeitos fixos e as co-variáveis, exceto o QTL; e "a" = efeito aditivo, gerado pelo programa QTLExpress. Os valores de aditividade $\left(c_{a}\right)$ e de dominância $\left(c_{d}\right)$ são funções das probabilidades condicionais do QTL considerando o genótipo dos locos e são calculados da seguinte forma:

$c_{a}=P(Q Q / M i)-P(q q / M i)$

$c_{d}=P(Q q / M i)$

em que: $\mathrm{P}(\mathrm{QQ})=$ probabilidade de os alelos do QTL serem homozigotos com origem da raça naturalizada Piau; P(qq) = probabilidade de os alelos do QTL serem homozigotos com origem da raça comercial; $\mathrm{P}(\mathrm{Qq})=$ probabilidade de os alelos do QTL serem heterozigotos.

\section{Resultados e Discussão}

Todos os marcadores utilizados neste estudo podem ser considerados eficientes nos estudos de características quantitativas, pois nestes estudos a aplicabilidade dos marcadores possui relação direta com o grau de polimorfismo dos marcadores (Tabela 3). Com exceção dos marcadores SW1897 (localizado no SSC16) e do S0120 (localizado no SSC18), classificados como moderadamente polimórficos, todos os demais marcadores podem ser considerados altamente polimórficos, pois apresentam valor de PIC maior que 0,5 (Bolstein et al., 1980).

Tabela 3 - Heterozigozidade observada $(\mathrm{Ho})$ e esperada $(\mathrm{He})$ e conteúdo de informação de polimorfismo (PIC) dos marcadores microssatélites usados no mapeamento dos cromossomos 16, 17 e 18 em suínos

\begin{tabular}{lcccc}
\hline Marcador & SSC $^{1}$ & Ho & He & PIC \\
\hline S0006 & 16 & 0,88 & 0,72 & 0,67 \\
SW977 & 16 & 0,72 & 0,62 & 0,54 \\
SW2517 & 16 & 0,69 & 0,59 & 0,50 \\
SW1897 & 16 & 0,40 & 0,36 & 0,32 \\
Média & & 0,67 & 0,57 & 0,50 \\
SW24 & 17 & 0,73 & 0,58 & 0,52 \\
SW2142 & 17 & 0,67 & 0,61 & 0,54 \\
S0359 & 17 & 0,70 & 0,60 & 0,59 \\
SW2427 & 17 & 0,78 & 0,67 & 0,61 \\
Média & & 0,72 & 0,61 & 0,56 \\
SW1984 & 18 & 0,77 & 0,73 & 0,69 \\
S0120 & 18 & 0,57 & 0,51 & 0,48 \\
S0177 & 18 & 0,69 & 0,65 & 0,60 \\
Média & & 0,68 & 0,63 & 0,59 \\
\hline
\end{tabular}

1 Cromossomo 
Tabela 4 - Números de alelos na geração F2 e meioses informativas para cada marcador

\begin{tabular}{lcc}
\hline Cromossomo/Marcador & Alelos* & Meioses informativas \\
\hline SSC16 & & \\
S0006 & $212,228,234,238,242$ & 645 \\
SW977 & $96,98,102$ & 604 \\
SW2517 & $161,171,181,187,189$ & 365 \\
SW1897 & $154,158,170$ & 403 \\
SSC17 & & \\
SW24 & $94,96,102,108,114$ & 613 \\
SW2142 & $130,140,144,146$ & 641 \\
SW359 & $253,259,263,267,275,277$ & 505 \\
SW2427 & $117,119,121,127,133$ & 727 \\
SSC18 & & \\
SW1984 & $138,142,146,150,160$ & 736 \\
S0120 & $150,152,154,162,164,168$ & 614 \\
S0177 & $139,143,149,151,163,167,171$ & 856 \\
\hline
\end{tabular}

*Alelos encontrados na geração F2.

O comprimento total dos mapas construídos foi de 166, 151 e 74 cM, respectivamente, para o SSC 16, o SSC17 e o SSC18 (Tabela 4).

O comprimento dos mapas de ligação (CRIMAP) para o SSC16 variou de 110 a 124,2 cM (Pierzchala et al., 2003; Bidanel et al., 2001). Para o SSC17, o comprimento encontrado varia de 90 a 97,8 cM (Pierzchala et al., 2003; Bidanel et al., 2001). Para o SSC18 os comprimentos de 48,7 a $89 \mathrm{cM}$ foram descritos (Dragos-Wendrich et al., 2003; Bidanel et al., 2001). Os comprimentos dos mapas de ligação deste estudo foram diferentes dos mapas encontrados na literatura pesquisada, o que está relacionado ao fato de que, além de não utilizarem o mesmo conjunto de marcadores, as populações utilizadas são diferentes. A diversidade genética dentro destas populações estaria influenciando a taxa recombinação (meiose), uma vez que o programa CRIMAP utiliza esta informação como base para fazer os mapas de ligação, o que refletiria em variações no comprimento dos mapas para as populações.

Foram identificados QTL nos cromossomos SSC16, SSC17 e SSC18 para as características de desempenho. Para todas as características, foram estimados os parâmetros do efeito aditivo, de dominância (Tabelas 5, 6 e 7)e de imprinting, que não foi significativo em todas as avaliações.

Dois QTL significativos foram identificados no SSC16 (Tabela 5): um associado à característica número de tetas $(\mathrm{P}<0,05$ e $\mathrm{F}=3,95)$ na posição de $126 \mathrm{cM}$ (IC 95\% entre 90 a $166 \mathrm{cM})$ e que explica $12,22 \%$ da fração aditiva da variação fenotípica dessa característica; e o outro a $1 \%$ do nível cromossômico $(\mathrm{F}=6,09)$, associado à característica peso aos 21 dias (Tabela 5), foi localizado em 26 cM (IC 95\% entre 0 e $48 \mathrm{cM}$ ) e explica $0,63 \%$ da fração aditiva da variação fenotípica da característica na região delimitada pelos marcadores S0006 e SW977 (Figura 1).

O QTL associado à característica número de tetas se localiza entre os marcadores SW2517 e SW1897 (Figura 1). O número de tetas totais, principalmente se todas forem funcionais nas matrizes, é uma característica importante e que influencia o desempenho dos leitões ao longo de suas vidas, pois é maior a chance de cada leitão se alimentar melhor, o que seria essencial para sua sobrevivência e seu desenvolvimento durante a fase pré-desmama. Não foram encontrados QTL associados ao número de tetas neste cromossomo na literatura pesquisada.

Para P21, o QTL também foi encontrado no SSC16 por Bidanel et al. (2001) em população formada a partir das raças suínas Meishan $\times$ Large White localizado a 34 cM. Esses autores também encontraram QTL para a característica ganho de peso médio diário do nascimento até as 3 semanas de idade na posição $31 \mathrm{cM}$. Apesar das localizações

Tabela 5 - Estatísticas F máximas (FMAX), com suas posições (cM), e estimativas dos efeitos aditivos e de dominância para as características de desempenho no SSC16

\begin{tabular}{|c|c|c|c|c|c|c|}
\hline \multirow{2}{*}{$\begin{array}{l}\text { Característica } \\
\text { Conversão alimentar dos } 77 \text { aos } 105 \text { dias de idade }(\mathrm{kg} / \mathrm{kg})\end{array}$} & \multirow{2}{*}{$\frac{\text { Posição }(\mathrm{cM})}{156}$} & \multirow{2}{*}{$\frac{\text { FMAX }}{3,31}$} & \multicolumn{2}{|c|}{ Aditivo $(E P)^{1}$} & \multicolumn{2}{|c|}{ Dominância (EP) } \\
\hline & & & 0,26 & $(0,13)$ & 0,28 & $(0,27)$ \\
\hline Consumo de ração dos 77 aos 105 dias de idade $(\mathrm{kg})$ & 66 & 0,92 & $-0,90$ & $(0,56)$ & $-0,21$ & $(0,82)$ \\
\hline Ganho de peso diário $(\mathrm{kg})$ & 165 & 1,72 & 0,05 & $(0,02)$ & 0,001 & $(0,04)$ \\
\hline Número de tetas & 126 & $3,95^{*}$ & 0,37 & $(0,16)$ & $-0,52$ & $(0,35)$ \\
\hline Peso ao nascer $(\mathrm{kg})$ & 125 & 0,83 & $-0,03$ & $(0,03)$ & 0,03 & $(0,07)$ \\
\hline Peso aos 21 dias $(\mathrm{kg})$ & 26 & $6,09 * *$ & 0,10 & $(0,19)$ & $-0,61$ & $(0,42)$ \\
\hline Peso aos 42 dias $(\mathrm{kg})$ & 121 & 1,51 & 0,43 & $(0,29)$ & 0,71 & $(0,58)$ \\
\hline Peso aos 63 dias $(\mathrm{kg})$ & 142 & 1,37 & $-0,52$ & $(0,55)$ & 2,24 & $(1,28)$ \\
\hline Peso aos 77 dias (kg) & 144 & 1,81 & $-0,53$ & $(0,62)$ & 3,17 & $(1,44)$ \\
\hline Peso aos 105 dias $(\mathrm{kg})$ & 152 & 1,28 & 1,04 & $(1,09)$ & 3,58 & $(2,40)$ \\
\hline Peso ao abate $(\mathrm{kg})$ & 132 & 2,66 & $-0,90$ & $(1,63)$ & 10,16 & $(3,69)$ \\
\hline Idade ao abate (dias) & 29 & 2,42 & 2,37 & $(1,24)$ & 3,91 & $(2,77)$ \\
\hline
\end{tabular}

\footnotetext{
*,**significativo, respectivamente, a $5 \%(F=3,95)$ e $1 \%(F=5,32)$, em nível de cromossomo.
}

1 'Erro-padrão. 
Tabela 6 - Estatísticas F máximas (FMAX), com suas posições (cM), e estimativas dos efeitos aditivos e de dominância para as características desempenho no SSC17

\begin{tabular}{|c|c|c|c|c|c|c|}
\hline \multirow{2}{*}{$\begin{array}{l}\text { Característica } \\
\text { Conversão alimentar dos } 77 \text { aos } 105 \text { dias de idade }(\mathrm{kg} / \mathrm{kg})\end{array}$} & \multirow{2}{*}{$\frac{\text { Posição }(\mathrm{cM})}{0}$} & \multirow{2}{*}{ FMAX } & \multicolumn{2}{|c|}{ Aditivo $(E P)^{1}$} & \multicolumn{2}{|c|}{ Dominância $(E P)^{1}$} \\
\hline & & & 0,13 & $(0,08)$ & 0,20 & $(0,14)$ \\
\hline Consumo de ração dos 77 aos 105 dias de idade $(\mathrm{kg})$ & 49 & 1,1 & $-0,34$ & $(0,62)$ & $-1,19$ & $(0,97)$ \\
\hline Ganho de peso diário (kg) & 151 & 1,83 & 0,02 & $(0,01)$ & 0,03 & $(0,02)$ \\
\hline Número de tetas & 2 & 1,4 & $-0,08$ & $(0,11)$ & 0,12 & $(0,20)$ \\
\hline Peso ao nascer (kg) & 151 & 3,1 & 0,05 & $(0,02)$ & $-0,05$ & $(0,02)$ \\
\hline Peso aos 21 dias $(\mathrm{kg})$ & 55 & 2,27 & 0,31 & $(0,15)$ & 0,41 & $(0,26)$ \\
\hline Peso aos 42 dias $(\mathrm{kg})$ & 49 & 2,21 & $-0,42$ & $(0,21)$ & $-0,03$ & $(0,33)$ \\
\hline Peso aos 63 dias $(\mathrm{kg})$ & 46 & $3,97 *$ & $-0,91$ & $(0,35)$ & 0,47 & $(0,60)$ \\
\hline Peso aos 77 dias $(\mathrm{kg})$ & 151 & $6,14 * *$ & 0,79 & $(0,34)$ & $-1,41$ & $(0,45)$ \\
\hline Peso aos 105 dias $(\mathrm{kg})$ & 151 & 3,61 & 1,58 & $(0,62)$ & $-1,22$ & $(0,83)$ \\
\hline Peso ao abate $(\mathrm{kg})$ & 23 & 0,93 & 0,38 & $(1,30)$ & $-2,55$ & $(2,81)$ \\
\hline Idade ao abate (dias) & 132 & 2,61 & 1,85 & $(1,09)$ & 4,52 & $(2,15)$ \\
\hline
\end{tabular}

*,**significativo, respectivamente, a $5 \%(F=3,95)$ e $1 \%(F=5,32)$ no cromossomo.

${ }^{1}$ Erro-padrão.

Tabela 7 - Estatísticas F máximas (FMAX) com suas posições (cM), e estimativas dos efeitos aditivos e de dominância para as características desempenho no SSC18

\begin{tabular}{|c|c|c|c|c|c|c|}
\hline \multirow{2}{*}{$\begin{array}{l}\text { Característica } \\
\text { Conversão alimentar dos } 77 \text { aos } 105 \text { dias de idade }(\mathrm{kg} / \mathrm{kg})\end{array}$} & \multirow{2}{*}{$\frac{\text { Posição }(\mathrm{cM})}{35}$} & \multirow{2}{*}{$\frac{\text { FMAX }}{1,2}$} & \multicolumn{2}{|c|}{ 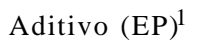 } & \multicolumn{2}{|c|}{ Dominância $(E P)^{1}$} \\
\hline & & & $-0,01$ & $(0,09)$ & 0,07 & $(0,14)$ \\
\hline Consumo de ração dos 77 aos 105 dias de idade $(\mathrm{kg})$ & 35 & 0,99 & $-0,56$ & $(0,62)$ & 1,17 & $(1,01)$ \\
\hline Ganho de peso diário $(\mathrm{kg})$ & 0 & 1,22 & 0,008 & $(0,018)$ & 0,05 & $(0,02)$ \\
\hline Número de tetas & 3 & 1,83 & $-0,22$ & $(0,11)$ & $-0,15$ & $(0,16)$ \\
\hline Peso ao nascer $(\mathrm{kg})$ & 58 & 3,33 & 0,06 & $(0,02)$ & $-0,08$ & $(0,05)$ \\
\hline Peso aos 21 dias $(\mathrm{kg})$ & 21 & $5,1 * *$ & 0,54 & $(0,15)$ & 0,67 & $(0,29)$ \\
\hline Peso aos 42 dias $(\mathrm{kg})$ & 74 & 0,43 & 0,07 & $(0,19)$ & 0,20 & $(0,27)$ \\
\hline Peso aos 63 dias $(\mathrm{kg})$ & 0 & 1,89 & 0,28 & $(0,31)$ & 0,94 & $(0,43)$ \\
\hline Peso aos 77 dias $(\mathrm{kg})$ & 0 & 2,95 & 0,38 & $(0,33)$ & 1,35 & $(0,47)$ \\
\hline Peso aos 105 dias $(\mathrm{kg})$ & 0 & 3,55 & 0,65 & $(0,61)$ & 2,74 & $(0,85)$ \\
\hline Peso ao abate $(\mathrm{kg})$ & 0 & 2,01 & 1,19 & $(0,88)$ & 1,89 & $(1,23)$ \\
\hline Idade ao abate (dias) & 0 & $3,82 *$ & $-1,29$ & $(0,77)$ & $-3,31$ & $(1,07)$ \\
\hline
\end{tabular}

*,**significativo, respectivamente, a $5 \%(F=3,95)$ e $1 \%(F=5,32)$ no cromossomo.

1 Erro-padrão.

próximas para o QTL descrito neste estudo e os citados na literatura, devem ser evitadas comparações diretas, pois as posições genômicas em cM dependem do tamanho do mapa de ligação usado, que, por sua vez, é afetado pelo histórico reprodutivo e genético das populações usadas no mapeamento e do número de marcadores usados.

Na porção inicial do SSC16, encontra-se o gene do receptor do hormônio de crescimento, que está diretamente relacionado aos efeitos deste hormônio e indiretamente relacionado aos efeitos do fator de crescimento semelhante a insulina-1 (IGF-I) e a uma enorme variedade de moléculas afins que formam o eixo regulador do crescimento pré e pós-natal. Faria et al. (2006), analisando associação de polimorfismo no gene do hormônio de crescimento $(\mathrm{GH})$ com características econômicas nesta mesma população, encontraram associação do SNP (polimorfismo de nucleotídeo único) G316A com o número de tetas direitas, peso coração, peso do pulmão, comprimento de carcaça pelo método Brasileiro, peso de paleta,
pH 24 horas e perda por gotejamento. Alonso et al. (2003) encontraram ligação do gene do receptor de prolactina com o microssatélite S0006 (também utilizado neste estudo) e concluíram que este gene poderia ser usado como marcador molecular para o ganho de peso médio diário. Assim, estes e outros genes a serem investigados poderiam estar associados aos QTL encontrados neste estudo no SSC16, como aos demais QTL encontrados na literatura relacionados com ganho de peso, peso em diferentes idades e consumo de ração.

Em ambos os QTL significativos, número de tetas (efeito aditivo $=0,37$ ) e peso aos 21 (efeito aditivo=0,10), o valor positivo do efeito aditivo do QTL implica que os alelos da raça Piau resultam em acréscimo nos fenótipos (Tabela 5), o que não era esperado, tendo em vista o baixo crescimento e o baixo número de leitões por leitegada nesta raça.

As curvas F significativas para as duas características de peso se localizaram nas extremidades opostas do SSC 17 (Figura 2), evidenciando a existência de genes nas regiões 


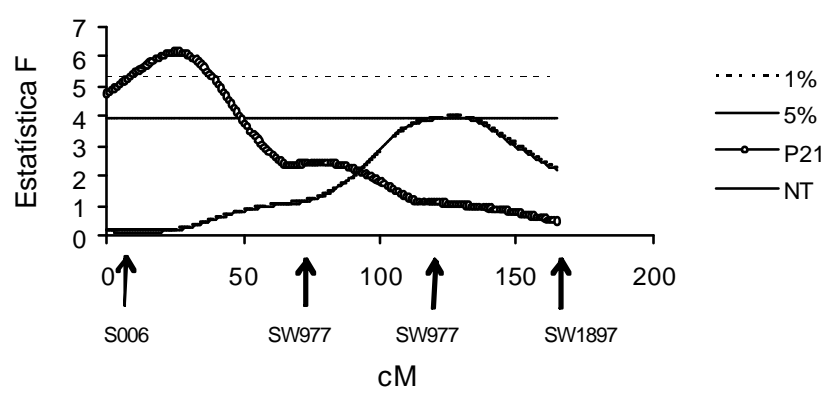

Figura 1 - Perfil de QTL para as características peso aos 21 dias de idade (P21) e número de tetas (NT). As linhas horizontais indicam os níveis de significância ao longo do cromossomo 16.

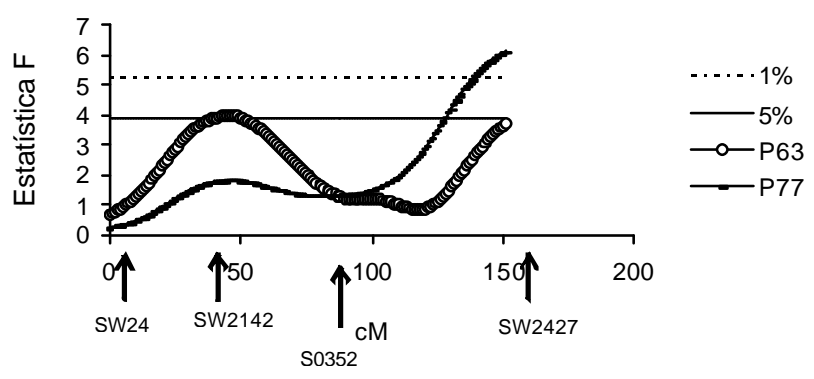

Figura 2 - Perfil de QTL para as características peso aos 63 dias de idade (P21) e peso aos 77 dias de idade (P77). As linhas horizontais indicam os níveis de significância ao longo do cromossomo 17.

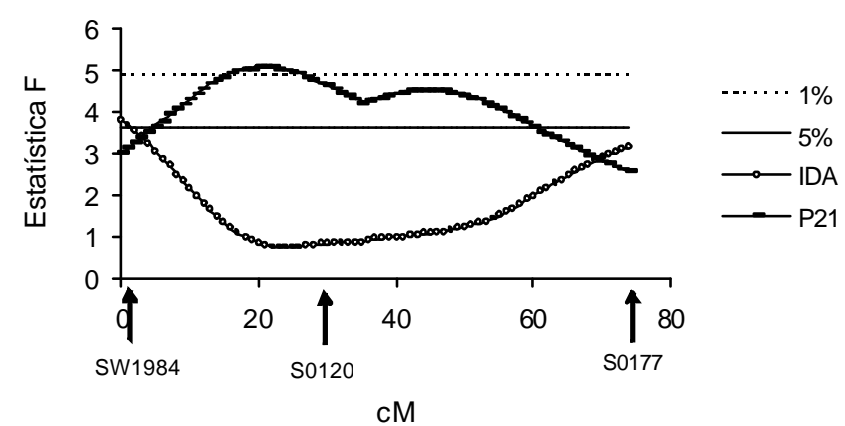

Figura 3 - Perfil de QTL para as características idade ao abate (IDA) e peso aos 21 dias de idade (P21). As linhas horizontais indicam os níveis de significância ao longo do cromossomo 18.

tanto centromérica quanto telomérica do SSC17 influenciand o características de peso. O FMAX para o QTL peso aos 63 dias de idade foi detectado próximo ao marcador SW2142 e o QTL para o peso aos 77 dias de idade entre os marcadores S0359 e SW2427 (Figura 2; Tabela 6). Para este cromossomo, existe ainda a necessidade de inclusão de outros marcadores na região telomérica, o que permitirá melhor delimitação do perfil dos QTL.

No SSC18, a característica IDA $(\mathrm{F}=3,82)$ foi significativa a $5 \%$ e explica $1,73 \%$ da fração aditiva da variação fenotípica da característica, localizando-se na posição de 0 cM (IC95\% entre 0 e 12). QTL também foi encontrado para a característica P21 $(\mathrm{F}=5,1)$, significativo a $1 \%$ no cromossomo, na posição de 21 cM (IC95\% entre 1 e 66), o que explica $26,50 \%$ da fração aditiva da variação fenotípica da característica. Verificou-se que os alelos Piau contribuem para aumento no fenótipo peso aos 21 dias (efeito aditivo $=0,54$ ) e aumento (efeito aditivo $=-1,29$ ) na idade ao abate em relação aos alelos comerciais (Tabela 7).

O QTL para P21 apresentou amplo intervalo de confiança (IC95\% entre 1 e $66 \mathrm{cM}$ ) pela presença de duas curvas F (Figura 3). Segundo Visscher et al. (2000), quanto maior a evidência de um QTL estar presente em determinada região, menor o intervalo de confiança. O grande intervalo de confiança para o QTL pode estar relacionado à presença de dois QTL, e não apenas um, e ao espaçamento entre os marcadores. Os estudos de Peixoto et al. (2006) ajudam a evidenciar a presença desses QTL no SSC18, que poderia estar associado ao gene da Leptina. Esses autores investigaram a associação de polimorfismos no gene da Leptina com características de produção em suínos, utilizando a mesma população deste estudo, e encontraram associação do SNP da Leptina T3469C com peso aos 21 dias (P21), P42, P63, P77, consumo, média de ganho diário, conversão alimentar, espessura de bacon e peso ao abate.

Entre os trabalhos de QTL pesquisados no SSC18, Dragos-Wendrich et al. (2003) encontraram QTL significativo $(\mathrm{P}<0,05)$ no genoma para a característica conversão alimentar na posição 54,2 cM. Além do gene da Leptina, no SSC18 também se encontram os genes do receptor do hormônio liberador do hormônio de crescimento (GHRHR), que age em receptores específicos na pituitária anterior para estimular a síntese e liberação de GH, o gene da proteína ligadora 3 do fator de crescimento semelhante à insulina (IGFBP-3), que possui múltiplas funções regulatórias de crescimento celular, e o gene do neuropeptídeo Y (NPY), que é estimulador do consumo alimentar, que poderiam estar associados aos QTL encontrados neste estudo e/ou aos demais QTL encontrados na literatura no SSC18.

Suínos Piau são conhecidos como porcos tipo banha. Apresentam alta deposição de gordura e pior conversão alimentar, em comparação a suínos de linhagens comerciais, e são considerados bancos de variabilidade genética por terem sofrido pouca ou nenhuma pressão de seleção. Em 
algumas características de peso em diferentes idades, seus alelos contribuíram positivamente para o fenótipo. $\mathrm{Na}$ idade ao abate (etapa final da produção), no entanto, a contribuição foi negativa. Ressalta-se que foram analisadas poucas regiões genômicas e que os fenótipos foram gerados pela interação entre diversos locos, localizados em diferentes regiões do genoma, além dos efeitos de ambiente.

\section{Conclusões}

Detectaram-se QTL nos cromossomos estudados após mensuração de várias características em população F2 gerada pelo cruzamento entre suínos machos da raça naturalizada Piau e fêmeas comercias (Landrace $\times$ Large White $\times$ Pietrain). Foram detectados QTL não descritos na literatura para número de tetas no SSC16, peso aos 63 dias de idade e peso aos 77 dias de idade no SSC 17, peso aos 21 dias e idade de abate no SSC18. Também foram detectados QTL descritos anteriormente em outras populações, como para peso aos 21 dias de idade no SSC16. QTL com curvas F pouco definidas poderão ser mais bem delimitados com a inclusão de mais marcadores. As informações dos QTL significativos encontrados servirão como base para estudos futuros, quando o mapeamento fino auxiliará na identificação de genes e no melhor entendimento dos fenótipos produtivos de suínos.

\section{Agradecimento}

À CAPES, à FAPEMIG, ao CNPq e à FINEP, pelo apoio financeiro. Ao Prof. Max F. Rothschild, coordenador do US Pig Genome Project, pela doação dos primers fluorescentes.

\section{Literatura Citada}

ALONSO, V.; SANTANA, B.A.A.; PIRAGE JR., W. et al. Efeito do gene receptor de prolactina sobre características quantitativas de interesse econômico em suínos. Brazilian Journal of Veterinary Research and Animal Science, v.40, p.366372, 2003.

BAND, G.O.; GUIMARÃES, S.E.F.; LOPES, P.S. et al. Relationship betweem the porcine stress syndrome gene and pork quality trait in F2 pigs resulting from divergent crosses. Genetics and Molecular Biology, v.8, n.1, p.88-91, 2005a.

BAND, G.O.; GUIMARÃES, S.E.F.; LOPES, P.S. et al. Relationship betweem the porcine stress Syndrome gene and carcass and performance trait in F2 pigs resulting from divergent crosses. Genetics and Molecular Biology, v.28, n.1, p.92-96, 2005 b.

BECKMANN, J.S.; SOLLER, M. Restriction fragment length polymorphisms in plant genetic improvement. In: BECKMANN, J.S.; OSBORN, T.C. (Eds.) Oxford surveys of plant molecular \& cell biology. Oxford University Press, 1990. v.3, p.196-250. BIDANEL, J.P.; MILAN, D.; IANNUCCELLI, N. et al. Detection of quantitative trait loci for growth and fatness in pigs. Genetic Selection Evolution, v.33, p.289-309, 2001.

BOTSTEIN, D.; WHITE, R.L.; SKOLNICK, M. et al. Construction of genetic linkage map in man using restriction fragment length polymorphisms. The American Journal of Human Genetics, v.32, p.314-331, 1980.

CHIN, E.C.L.; SENIOR, M.L.; SHU, H. et al. Maize simple repetitive DNA sequences: abundance and allele variation. Genome, v.39, p. 866-873, 1996.

CHURCHILL, G.A.; DOERGE, R.W. Empirical threshold values for quantitative trait mapping. Genetics, v.138, p.963-971, 1994.

DRAGOS-WENDRICH, M.; STRATIL, A.; HOJNY, J. et al. Linkage and QTL mapping for Sus scrofa chromosome 18. Journal of Animal Breeding and Genetics, v.120, p.138-143, 2003.

FARIA, D.A.; GUIMARÃES, S.E.F.; LOPES, P.S. et al. Association between G316A growth hormone polymorphism and economic traits in pigs. Genetics and Molecular Biology, v.29, n.4, p.634-640, 2006.

GREEN, P.; FALLS, K.; CROOKS, S. CRIMAP Documentation version 2.4. St. Louis: Washington University School of Medicine, 1990. Disponível em: <http://linkage.rockefeller.edu/ soft/crimap/intro1.html>. Acesso: 1/1/2007.

HALEY, C.S.; KNOTT, S.A.; ELSEN, J.M. Mapping quantitative trait loci in crosses between outbred lines using least squares. Genetics, v.36, p.1195-1207, 1994.

LIU, B.H. Statistical genomics: linkage, mapping and QTL analysis. New York: CRC Press Science, 1998. 611p.

MARSHALL, T.C.; SLATE, J.; KRUUK, L.E.B. et al. Statistical confidence for likelihood-based paternity inference in natural populations. Molecular Ecology, v.7, p.639-655, 1998.

PLASTOW, G.S. Molecular genetics in the swine industry. In: SIMPÓSIO NACIONAL DE MELHORAMENTO ANIMAL, 2000, Belo Horizonte. Anais... Belo Horizonte: 2000. p. $21-30$.

PEIXOTO, J.O.; GUIMARÃES, S.E.F.; LOPES, P.S. et al. Associations of Leptin gene polymorphisms with production traits in pig. Journal Animal Breeding and Genetics, v.123, p.1-6, 2006

PÉREZ-ENCISO, M.; CLOP, A.; NOGUERA, J.L. et al. A QTL on pig chromosome 4 affects fatty acid metabolism: evidence from a Iberian by Landrace intercross. Journal of Animal Science, v.78, p.2525-2531, 2000.

PIERZCHALA, M.; CIESLAK, D.; REINER, G. et al. Linkage and QTL mapping for Sus scrofa chromosome 17. Journal of Animal Breeding Genetics, v.120, p.132-137, 2003.

STATISTICAL ANALYSIS SYSTEM - SAS. SAS/STAT ${ }^{\circledR}$ user's guide: version 6. 4.ed. Cary: SAS Institute, 2000. (CD-ROM).

SEATON, G.; HALEY, C.S.; KNOTT, S.A. et al. QTLEXPRESS: mapping quantitative trait loci in simple and complex pedigrees. Bioinformatics, v.18, n.2, p.339-340, 2002. Disponível em: <http://qtl.cap.ed.ac.uk>. Acesso: 1/1/2007.

VISSCHER, P.; PONG-WONG, R.; WHITTEMORE, C. et al. Impact of biotechnology on (cross) breeding programmers in pigs. Livestock Production Science, v.65, n.1-2, p.57-70, 2000. 